\title{
AN INTERACTIVE APPLICATION USING C-SHARP LANGUAGE FOR PREDICTING CUMULATIVE INFILTRATION RATE OF WATER IN SOIL
}

\author{
AL-SULAIMAN,M. A. ${ }^{1}$ and A. M. ABOUKARIMA ${ }^{2}$ \\ 1. Community College, Huraimla, Shaqra University, Saudi Arabia \\ 2. Agricultural Engineering Research Institute, ARC, Egypt
}

(Manuscript received 20 September 2016)

\begin{abstract}
$\mathrm{T}$ he objective of this study was to develop an interactive application using C-Sharplanguage to predict cumulative infiltration rate of water in a soil.Cumulative infiltration rate seems to be very simple issue, but field determination of it is very tedious and time consuming task due to many factors affectingit. Thus, researchers should be encouraged to develop a simple and accurate model to predict the cumulative infiltration. The actual measurements of infiltrationin this study were obtained using double ring infiltrometer.The measurements were conducted in the field on different soil textures namely sand, sandy loam, loam and loamy sand. Moreover, different water qualities were utilized. The inputs to the interactive application were soil electric conductivity, soil sodium adsorption ratio, percentage of organic matter in the soil,initial soil water contents, initial soil bulk density, sodium adsorption ratio of water, electric conductivity of water and an index to represent soil texture.The mean error between actual and predicted cumulative infiltration rate by the help of the developed interactive application after three hours was-39.25 $\mathrm{mm}$. Consequently, the developed C-Sharp application is recommended for estimating cumulative infiltration rate in soilsto provide data for irrigation water management.
\end{abstract}

Key words: Modeling, double ring, artificial neural network.

\section{INTRODUCTION}

Water infiltration of rainfall or irrigation is an important topic of soil and water conservation in semi-arid regions. Furthermore, it controls leaching, runoff and crop water availability (Franzluebbers, 2002). Soil texture, soil structure, organic matter in the soil, management and type of soil layers are some factors which affect infiltration rate (Skandariniaet al., 2005).Additionally, infiltration rate depends on amount of the initial soil moisture content, the soil slope, the soil roughness, the type of vegetative cover, the water depth, the soil and water temperature, the applied water quality, the amount of dissolved salts particularly exchangeable sodium in water and soil and the dispersion of the soil surface particles (Mazloom and Foladmand, 2013). Moreover, infiltration rate of water into a soil can be greatly influenced by the quality of the 
irrigation water, degree of compaction andthe organic matter content in the soil (Ayers and Westcot, 1994).

Cumulative infiltration rate is the total quantity of water that enters the soil in a given time. Thus, it commonly used in evaluating the infiltration characteristics of a soil. On the other hand, empirical equations are used to describe infiltration process of a soil through determining their empirical constants. Theempirical equations that used to describe infiltration process of a soilare ranged from simple to complex and the famous one is Kostiakov's infiltration model. The empirical constants of Kostiakov's infiltration model were obtained statistically by several researches (Ulomaet al., 2014; Al-Sulaiman et al., 2015). Recently, artificial neural networks technique has been applied in prediction of soil infiltration with great success (Matte et al., 2015).

Prediction of infiltration in a soil is of prime importance in irrigation studies as it influences the application rate of irrigation water(Jejurkar and Rajurkar, 2015). However, infiltration seems to be very simple topic, but field determination of it is very tedious and time consuming task. So, researchers are encouraged to developa simple and accurate model to predict the cumulative infiltration rate due to many factors affecting it. Thus, in this research the empirical constants of Kostiakov equation (Kostiakov, 1932) for cumulative infiltration rate were predicted by the help ofan artificial neural network (ANN) model. The obtained ANN weights after training process were formulated into C-Sharp application for estimating cumulative infiltration rate easily based on soil and water characteristics. This proposed simple-to-use computer application can be utilized as a good tool for soil scientists and agricultural engineers to have a rapid data about infiltration at wide range of soil and irrigation water characteristics without the necessity to conduct field experiments.

\section{MATERIALS AND METHODS}

\section{Characteristics of the used soil and water}

The experimental sites were located in different regions in Saudi Arabia. The soil particle sizes were determined by using the laboratory standard methods. Prior to infiltration run, five soil samples were collected randomly from the top of $21 \mathrm{~cm}$ using soil auger from each site. These soil samples were bulked for the determination of the initial soil moisture content and soil bulk density using standard laboratory procedures. Chemical analysis for each soil and for each water type was conducted. Nine soil texture and twenty water types with different characteristics were considered in this study. Sodium adsorption ratio (SAR) for the soil and the water were calculated from the chemical analysis using the following formula (Suarez et al., 2006): 
$S A R=\frac{N a^{+}}{\sqrt{\frac{1}{2}\left(C a^{++}+M g^{++}\right)}}$

Where $\mathrm{Na}^{+}, \mathrm{Ca}^{++}$and $\mathrm{Mg}^{++}$represent concentrations of sodium, calcium and magnesium in a soil or in waterexpressed in milliequivalents per liter (meq/L).Also, electric conductivity (EC) for soil and water was measured in $\mathrm{dS} / \mathrm{m}$.

To make any mathematicalmodel more universal, a variable describing the soil type was added to the model (Altendorf et al., 1999). By browsing through literatures, different formulas were found to represent soil components (sand, silt, and clay) in one numeric value to be used in the mathematical models. In this study, soil texture index (STI) which developed by Oskoui and Harvey (1992) was selected to represent soil texture components and it was calculated as follows:

$S T I=\frac{\log \left(S_{i}^{C C_{a}}\right)}{100}$

Where $S_{i}$ and $C C_{a}$ are $\%$ of silt and clay fractions in the soil, respectively. Meanwhile, the sand fraction is represented implicitly since the sum of sand, silt and clay fractions is always constant. Oskoui and Harvey (1992) showed that the STI reflects the effects of all three of the soil fractions. The STI produces unique numbers for every combination of sand, silt and clay contents. The raw data were illustrated in AlSulaiman et al. (2015) for soil and water characteristics. Meanwhile, Table (1) shows minimum, maximum and stranded deviation of the soil and water characteristics.

Table 1. Minimum, maximum and stranded deviation of soil and water characteristics.

\begin{tabular}{|c|c|c|c|c|c|c|c|c|}
\hline \multirow{2}{*}{$\begin{array}{c}\text { Statistical } \\
\text { parameters }\end{array}$} & STI & MC & BD & ECW & SARw & ECS & SARs & OM \\
\cline { 2 - 9 } & $(--)$ & $(\%, \mathrm{db})$ & $\left(\mathrm{g} / \mathrm{cm}^{3}\right)$ & $(\mathrm{dS} / \mathrm{m})$ & $(---)$ & $(\mathrm{dS} / \mathrm{m})$ & $(---)$ & $(\%)$ \\
\hline Minimum & 0.0060 & 3.28 & 1.25 & 0.22 & 1.64 & 1.06 & 2.00 & 0.26 \\
\hline Maximum & 0.3722 & 16.92 & 1.76 & 5.28 & 8.80 & 91.10 & 57.60 & 2.62 \\
\hline $\begin{array}{l}\text { Standard } \\
\text { deviation }\end{array}$ & \pm 0.1197 & \pm 3.03 & \pm 0.13 & \pm 1.38 & \pm 1.96 & \pm 27.50 & \pm 16.51 & \pm 0.78 \\
\hline
\end{tabular}

ECs=Electric conductivity of soil, SARs=Soil sodium adsorption ratio, OM=Organic matter in the soil,MC=Initial soil water contents, $B D=I n i t i a l$ soil bulk density, SARw=Sodium adsorption ratio of water, $\mathrm{ECW}=$ Electric conductivity of water and $\mathrm{STI}=$ Soil texture index calculated by Eq.2.

\section{Experimental procedures}

The double-ring infiltrometer was used to get infiltration readings in the field. Different water qualities were transported to each site in two barrels with capacity of 100 liters. The double-ring infiltrometer $30 \mathrm{~cm}$ high was used and it had inner and 
outer galvanized iron rings of diameters $30 \mathrm{~cm}$ and $60 \mathrm{~cm}$, respectively. The rings were driven at about $10 \mathrm{~cm}$ deep in the soil by using falling weight type hammer striking on a wooden plank placed on top of ring uniformly without or undue disturbance to soil surface. Water was poured slowly into the inner ring. The outer ring, which acts as a buffer, was also filled with water to the same height in order to minimize the lateral seepage from the inner ring. A graduated metal rulerwas placed in the inner ring. The ruler was adjusted to the desired level to which water was to be added. A digital stopwatch was used to note the time the water begins to infiltrate. The soil intake rate was measured directly by observing the rate at which the water level declined with respect to time. The experiments were carried out for a period of 180 minutes as indicated by Uloma et al. (2014). This was based on the fact that infiltration usually takes $120-360$ minutes for the process to reach steady state as reported byLili et al. (2008).The observations for infiltration rate were carried out on the inner ring. A field experiment was conducted to test the effect of water quality on the infiltration rate of soils having different properties. Three infiltration measurements were conducted using each water quality and average was taken later.

\section{Kostiakov's infiltration model}

Despite the availability of a large number of infiltration models, some of the available empirical models have been quite popular and frequently used in infiltration experiments because of their simplicity and yielding reasonably satisfactory results (Uloma et al., 2014). Kostiakov's infiltration model (Kostiakov, 1932)is derived using the data observed either in the field or the laboratory. Kostiakov's infiltration model suggested a formula which assumed that at time $T=0$, the infiltration rate is infinite and at time $T=\infty$, the rate approaches zero. The Kostiakov's infiltration model is given bythe following formula:

$Z=\kappa T^{\alpha}$

Where $\mathrm{T}$ is the time elapsed for the experiment (hr), Zis the cumulative infiltration rate $(\mathrm{mm}), \alpha$ and $\kappa$ are empirical constants that are site specific and depend on different parameters (Uloma et al., 2014). The parameter $\alpha$ was accepted by most authors to be less than one (Moroke et al., 2009). Unit of the empirical constant $\kappa$ is $\mathrm{mm} / \mathrm{hr} r^{\alpha}$ and the empirical constant $\alpha$ is without unit. As a Kostiakov infiltration model is an empirical one, no physical meanings are attached to its associated constants (Khaliq et al., 1994). To determine the constants $\alpha$ and $\kappa$, the log of Eq. (3) was taken, then the Kostiakov's constants $\alpha$ and $\kappa$ were determined graphically. However, the slop linear relation of $Z$ and $T$ presented the value of $\alpha$, while $\log \kappa$ 
presented the intercept of $Z$ axis. The value of $\kappa$ was obtained from the anti-log $\kappa$. i.e.

$\kappa=10^{\log \kappa}$

In this study, 180 values for the Kostiakov's infiltration model constants $\alpha$ and $\kappa$ were calculated. The raw data for these values were shown in Al-Sulaiman et al. (2015). Table (2) shows minimum, maximum and stranded deviation of the calculated Kostiakov's infiltration model constants $\alpha$ and $\kappa$.

Table 2. Minimum, maximum and stranded deviation of the calculated infiltration model parameters $\alpha$ and $\kappa$.

\begin{tabular}{|c|c|c|}
\hline \multirow{2}{*}{ Statistical parameters } & \multicolumn{2}{|c|}{ Kostiakov's infiltration model (Eq. 3) } \\
\cline { 2 - 3 } & $\alpha(-)$ & $\kappa\left(\mathrm{mm} / \mathrm{hr} \mathrm{c}^{\alpha}\right)$ \\
\hline Minimum & 0.2375 & 3.663 \\
\hline Maximum & 0.8722 & 202.91 \\
\hline Standard deviation & \pm 0.0780 & \pm 43.66 \\
\hline
\end{tabular}

Artificial neural network (ANN) for modeling the empirical constants $(\kappa)$ and $(\alpha)$

Briefly, an ANN model operates by propagating various linear combinations of the input values through a series of one or more layers consisting of processing elements or neurons. The nonlinear aspect of the modeling is incorporated in the transfer function, which is applied to the linear combination at each layer. The network learns through back propagating the error. The training data set contains the desired output vector associated with each input vector. On completion of the forward propagation, the desired network output is compared with the actual output. A gradient descent process is used to adjust the weights such that the error will be decreased. The objective at each step is to adjust weights to reduce the error, not to find the weights, which will minimize error. Typically, the network must run in the training mode through great much iteration, and a reactively large set of training data may be required (Altendorf et al., 1999). The mathematics of the back propagation algorithm was described in Haykin (1999).

In this study, commercially available software called QNET 2000 was employed (Vesta Services, 2000). This software is a Windows-based package, which supports standard back-propagation algorithm for training purposes. QNET 2000 operates via a graphical user interface that enables the user to load the training and test sets, design the network architecture and feed values for the training parameters. It must be noted that because the variables (input or output) presented were of different orders 
of magnitude, all of the original input or output parameters were normalized between 0.15 and 0.85 before entering into the network structure using the following equation: $X=\frac{\left(t-x_{\min }\right)}{\left(x_{\max }-x_{\min }\right)} \times(0.85-0.15)+0.15$

Where $t$ is the original values of input and output parameters, $X$ is the normalized value; $x_{\min }$ and $x_{\max }$ are the minimum and the maximum values of the input and the output parameters in training data set, respectively. The training data set was used to compute the network parameters. The testing data set was used to ensure robustness of the network parameters. In the study, trial and error approach was used to determine the optimum neurons in the hidden layers of the network. Transfer function was also varied; however, they were sigmoid and hyperbolic tangent (tanh) in the hidden layers. The training data set consisted of 180 patterns for empirical constants ( $\alpha$ and $\kappa$ ) of cumulative infiltration rate corresponding to different 8inputs, which were electric conductivity of soil, soil sodium adsorption ratio, initial soil water content, soil texture index, soil bulk density, organic matter in the soil, electric conductivity of water and sodium adsorption ratio of water. The output (target) variable in this study was empirical constant $(\kappa)$ and empirical constant $(\alpha)$ of Kostiakov cumulative infiltration rate equation (Eq.3).

Preliminary trails indicated that one hidden layer network performed better results to learn and predict the correlation between input and output parameters. To determine the optimal number of neurons in the hidden layer, training was used for 8$\mathrm{n} 1-1$ architectures. The number of neurons in the hidden layer (n1) was studied from 1 to30. Results showed that among the various structures, the best training performance to predict empirical constant $(\kappa)$ belonged to the 8-20-1 ANN structure. Meanwhile, the best training performance to predict empirical constant $(\alpha)$ belonged to the 8-25-1 ANN structure. However, the best ANN model was elected based on the highest correlation coefficient and the lowest training error. Training error for empirical constant $(\kappa)$ was 0.031834 and it was 0.026145 for empirical constant ( $\alpha$ ).Table (3) illustrates statistics criteria of the best ANN models from QNET 2000software after training process to predict empirical constants ( $\alpha$ and $\kappa$ ).

Table 3. Statistics criteria of the best ANN models from QNET 2000 software after training process to predict empirical constants ( $\alpha$ and $\kappa$ ).

\begin{tabular}{|c|c|c|c|c|}
\hline \multirow{2}{*}{$\begin{array}{c}\text { Empirical } \\
\text { constants }\end{array}$} & Standard deviation & Bias & Maximum error & Correlation coefficient $(r)$ \\
\cline { 2 - 5 } & & & \\
$\kappa\left(m m / h r^{\alpha}\right)$ & \pm 50.2913 & -0.25652 & 9.061 & 0.97813 \\
\hline$\alpha(--)$ & \pm 0.02371 & $-1.52 \mathrm{E}-05$ & 0.15275 & 0.95318 \\
\hline
\end{tabular}




\section{Evaluation of ANN models predictability}

The performance of an ANN model can be attributed to its structural and functional characteristics (Singh et al., 2013), thus the ANN output error between the actual and the predicted values should be evaluated. Popular error criteria for performance measure are mean absolute error (MAE) and mean relative error (MRE) which were used and they are calculated as follows:

$$
\begin{aligned}
& M A E=\frac{1}{N} \times \sum_{i=1}^{i=N}\left|K_{\text {viobs }}-K_{\text {vipre }}\right| \ldots \ldots . \\
& M R E=\frac{100}{N} \times \sum_{i=1}^{i=N}\left(\frac{K_{\text {vipre }}-K_{\text {viobs }}}{K_{\text {iobs }}}\right) .
\end{aligned}
$$

Where $K_{\text {viobs }}$ and $K_{\text {vipre }}$ were calculated (observed) and predicted empirical constants $(\alpha$ and $\kappa)$, respectively and $\mathrm{N}$ is number of observations. The correlation coefficient ( $r$ ) was selected to be a criterion for measuring the linear correlation between the calculated and the predicted values.

\section{C-Sharp application}

C-Sharp programming language available under NET programming environment has been used for developing an interactive computer application to predict empirical constants $(\alpha$ and $\kappa)$. This application has been developed keeping in view its user friendliness and easily operable. C-Sharp language was chosen because it is a generic portable language and could be run on other operating systems (Post, 2007). The current C-Sharp application was developed based on the weights obtained from the developed ANN models for empirical constants ( $\alpha$ and $\kappa$ ) during training stage. These weights were formulated into equations with the help of programming by $\mathrm{C}$ Sharp to be easily used. The developed C-Sharp application was validated with experimental data to ascertain its suitability for ( $\alpha$ and $\kappa$ ) predictions and then cumulative infiltration rate. Fig. (1) shows screenshot of the inputs screen, besides, Fig. (2) indicates screenshot of the output screen.

\section{RESULTS AND DISCUSSION}

\section{Performance of the developed ANN models}

A comparison of the empirical constants ( $\alpha$ and $\kappa$ ) of cumulative infiltration rate equation (Eq. 3 ) values predicted using the developed ANN models with those calculated graphically is presented point by point in Figs. (1 and 2) for training data set for the empirical constants $(\kappa)$ and the empirical constant $(\alpha)$, respectively. Better agreement of points presented in Figs. (3 and 4) with a straight line (1:1) which means better agreement between the calculated and the predicted points. 


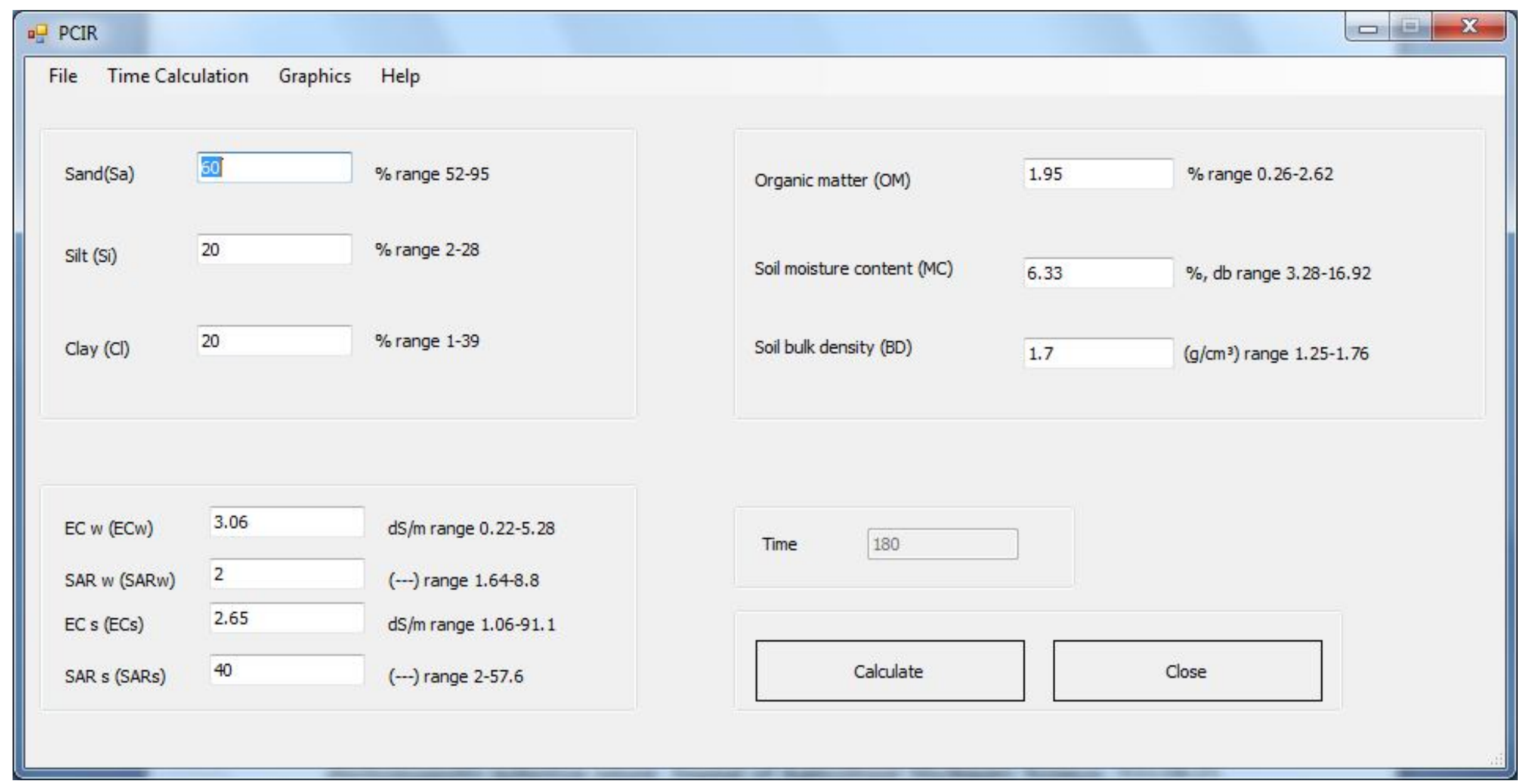

Fig. 1. Screenshot of the inputs screen in the developed C-Sharp application. 


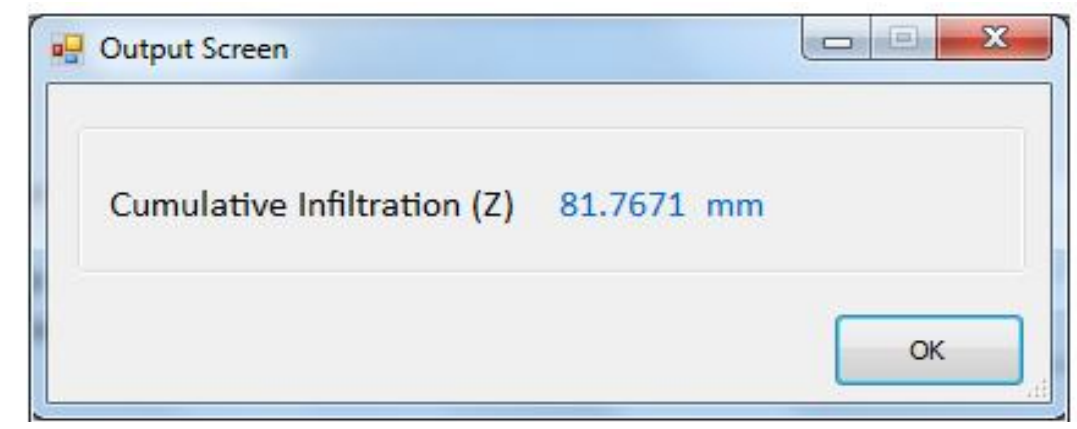

Fig. 2. Screenshot of the output screen in the developed C-Sharp application.

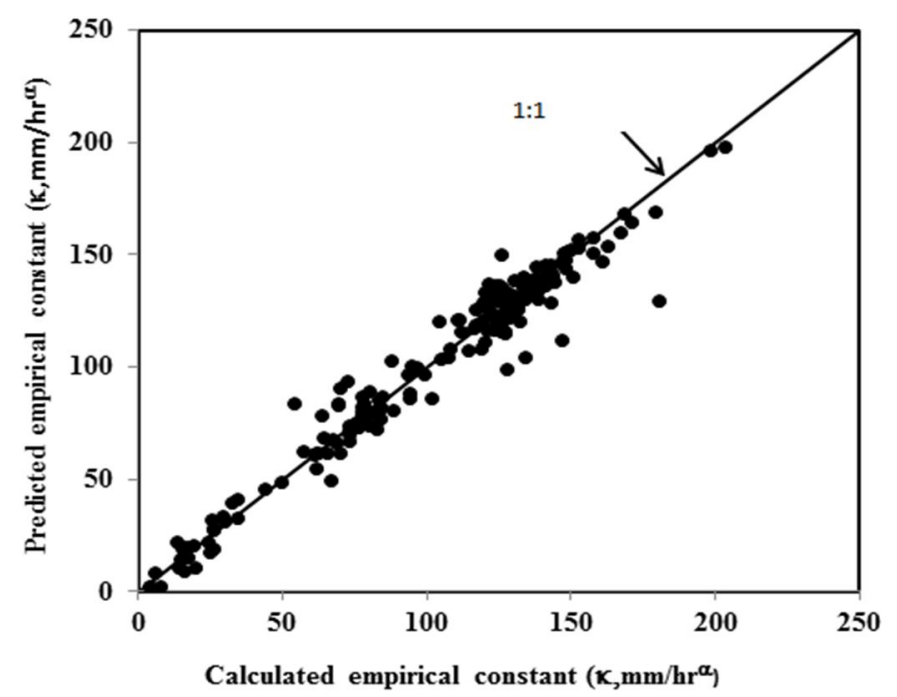

Fig. 3. Relationship between the predicted empirical constant $(\kappa)$ from the developed ANN model and the empirical constant $(\kappa)$ calculated graphically for training patterns.

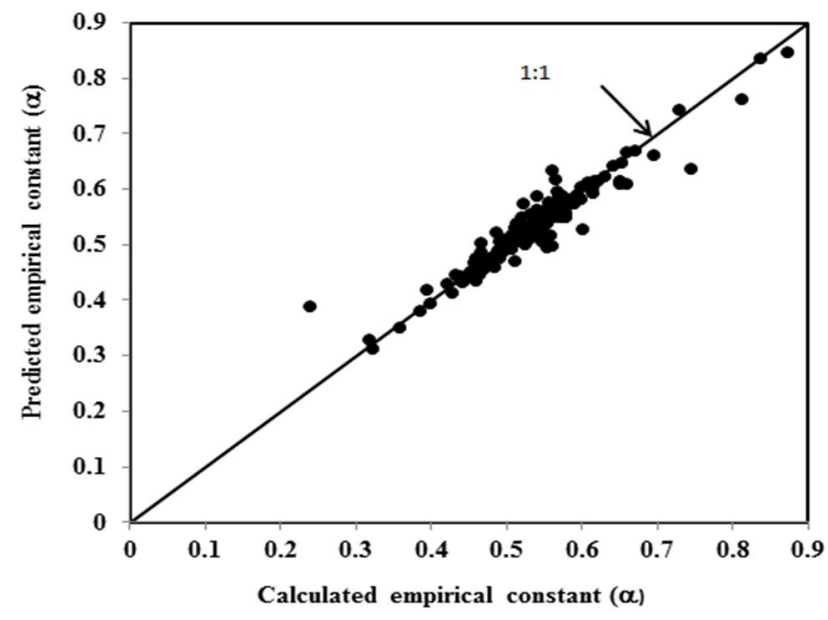

Fig. 4. Relationship between the predicted empirical constant ( $\alpha$ ) from the developed ANN model and the empirical constant $(\alpha)$ calculated graphically for training patterns. 
The maximum errors between the calculated graphically empirical constants $(\kappa)$ and $(\alpha)$ and the predicted values using the developed ANN models was 9.061 $\mathrm{mm} / \mathrm{hr} r^{\alpha}$ and 0.15275 as shown in Table (3) during training phase, respectively. However, the predictability of the developed ANN models for prediction of $(\alpha)$ and $(\kappa)$ was tested during testing process by calculating ofmeanabsolute error (MAE), mean relative error (MRE) and correlation coefficient. However, Table (4) shows values of meanabsolute error (MAE), mean relative error (MRE) and correlation coefficient $(r)$ during testing process of the developed ANN models for prediction of empirical constants ( $\alpha$ and $\kappa$ ) of cumulative infiltration rate equation (Eq. 3). From Table (4), it is clear that MRE and MAE values showed a small error between the calculated graphically and the predicted values of $(\alpha)$ and $(\kappa)$, suggesting that the employed ANN models were very accurate in predicting the values of the two empirical constants at any values of the independent variables, falling within the range of values in the study. MAE and MRE for $(\kappa)$ were $4.835 \mathrm{~mm} / \mathrm{hr}{ }^{\alpha}$ and $0.371 \%$, respectively. Meanwhile, MAE and MRE for $(\alpha)$ were 0.0145 and $-1.148 \%$, respectively.

Table 4. Meanabsolute error (MAE), mean relative error (MRE) and correlation coefficient $(r)$ during testing process of the developed ANNmodels for prediction of empirical constants ( $\alpha$ and $\kappa$ ) of cumulative infiltration rate equation (Eq. 3).

\begin{tabular}{|c|c|c|}
\hline Error criteria & The empirical constant $(\boldsymbol{K})$ & The empirical constant $(\alpha)$ \\
\hline (MAE) & $4.835\left(\mathrm{~mm} / \mathrm{h} r^{\alpha}\right)$ & $0.0145(--)$ \\
\hline (MRE) & $-0.371(\%)$ & $-1.148(\%)$ \\
\hline (r) & 0.909 & 0.720 \\
\hline
\end{tabular}

\section{Contribution of inputs on predicted the empirical constants $(\alpha)$ and $(\kappa)$} with the developed artificial neural network models

Infiltration problems could not be attributed to any specific soil chemical or physical property. Under the given conditions, infiltration seemed to be determined by a combination of soil properties, i.e. EC, SAR, type of clay mineral and bulk density as reported by Haghnazari et al. (2015). So, thecontribution analysis for how the change in each input in the developed ANN infiltration models, changes the output prediction is significant task to display the importance of each variable. In this study, the QNET 2000software provided a contribution calculation for how the change in each input, changes the output prediction. Consequently, the contribution percentage of the eight input variables to the outputs was calculated using the developed ANNmodels and the results are illustrated in Table (5). It can be deduced from Table (5) that the major 
contribution to the the empirical constant $(\kappa)$ was attributed to the parameter of soil electric conductivity with a contribution percentage of $16.82 \%$ and this means areas of saline soils need to be managed differently than areas of no saline soils (Haghnazari et al., 2015). Myburgh and Howell (2012) also indicated that infiltration is affected by soil salinity and it decreased as the soil salinity increased.

Table 5. Contribution percentage of eight independent variables for prediction of the empirical constants $(\alpha)$ and $(\kappa)$ by the help of the developed ANN models.

\begin{tabular}{|c|c|c|}
\hline \multirow{2}{*}{ Input variables } & \multicolumn{2}{|c|}{ Contribution (\%) } \\
\cline { 2 - 3 } & Empirical constant $(\kappa)$ & Empirical constant $(\alpha)$ \\
\hline Soil texture index (STI, dimensionless) & 16.28 & 14.94 \\
\hline Initial soil water content (MC, \%,db) & 11.32 & 12.17 \\
\hline Soil bulk density (BD, $\left.\mathrm{g} / \mathrm{cm}^{3}\right)$ & 10.21 & 10.09 \\
\hline Water electric conductivity (ECw, dS/m) & 9.95 & 10.57 \\
\hline Water sodium adsorption ratio (SARw,---) & 12.99 & 12.81 \\
\hline Soil electric conductivity (ECs,dS/m) & 16.82 & 13.02 \\
\hline Soil sodium adsorption ratio (SARs, ---) & 11.79 & 12.20 \\
\hline Organic matter in the soil (OM,\%) & 10.64 & 14.20 \\
\hline
\end{tabular}

The major contribution to the empirical constant $(\alpha)$ was attributed to the variable of soil texture indexwith a contribution percentage of $14.94 \%$ as shown in Table (5), however, soil texture (percentage of sand, silt, and clay) was the major inherent factor affecting infiltration. Moreover, the infiltration is strongly influenced by the soil texture, i.e the relative proportions of sand, silt and clay (Haghnazari et al., 2015) since water moves more quickly through large pores of sandy soil than it does through small pores of clayey soil, especially if clay is compacted.The rest of input variables were nearly equal in the contribution percentage to the empirical constant $(\alpha)$ and the empirical constant $(\kappa)$.

\section{Performance of the developed C-Sharpapplication}

To validate the developed C-Sharp application to predict cumulative infiltration rate, an interface window for the required inputs data was developed.In Table (6), thepredicted final cumulative infiltration rate after three hours(Z3) by the application wasobtained for soil having sand, silt and clay percentage of $80 \%, 13 \%$ and $7 \%$, respectively and having soil electric conductivity, soil sodium adsorption ratio and 
organic matter of $10.86 \mathrm{dS} / \mathrm{m}, 8.2$ and $1.34 \%$, respectively using different water characteristics and different initial soil moisture contents and soil bulk densities. It is clear from Table (6) that the mean error between actual and predicted cumulative infiltration rate after three hours was $-39.25 \mathrm{~mm}$. Moreover, when the inputs variables of sand, silt, clay, water electric conductivity, water sodium adsorption ratio, soil electric conductivity, soil sodium adsorption ratio, organic matter in the soil, initial soil water content, soil bulk density and the required time were $60 \%, 20 \%, 20 \%, 3.06$ $\mathrm{dS} / \mathrm{m}, 2,2.65 \mathrm{dS} / \mathrm{m}, 40,1.95 \%, 6.33 \% \mathrm{db}, 1.70 \mathrm{~g} / \mathrm{cm}^{3}$ and $180 \mathrm{~min}$, respectively, initially,the application started up to estimate soil texture index to be 0.260206 using Eq. (2), then it directed to estimate both the constant $\kappa$ to be $71.73 \mathrm{~mm} / \mathrm{hr}{ }^{\alpha}$ and the constant $\alpha$ to be 0.11855 . By substitution of the two constants in the Eq.(3) and at time of 180 min inside the application, the estimated final cumulative infiltration rate was $81.7671 \mathrm{~mm}$. 
Table 6. Final cumulative infiltration rate after three hours (measured,calculated graphically and predicted using C-Sharp application), the calculated empirical constants of Kostiakov equation, the predicted empirical constants of Kostiakov equation using the developed C-Sharp application for soil having sand, silt and clay percentage of $80 \%, 13 \%$ and $7 \%$, respectively and having soil electric conductivity, soil sodium adsorption ratio and organic matter of $10.86 \mathrm{dS} / \mathrm{m}, 8.2$ and $1.34 \%$, respectively using different water characteristics and different initial soil moisture contents and soil bulk densities.

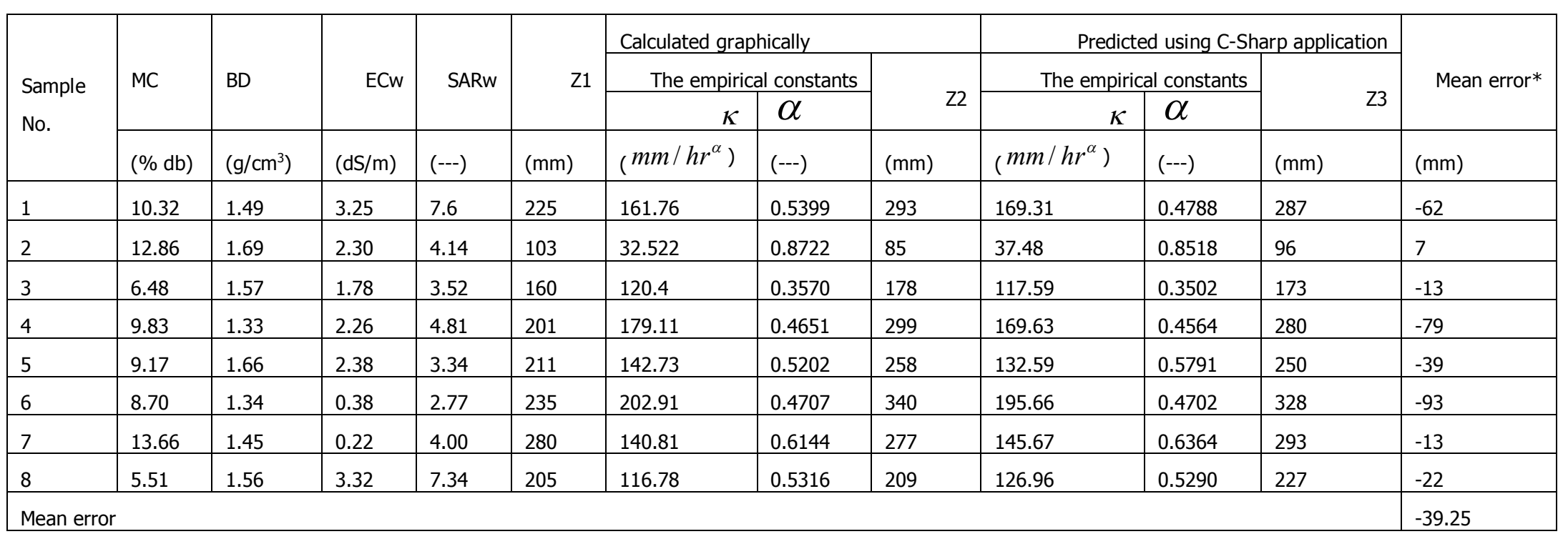

$\mathrm{Z1}=$ final cumulative infiltration rate after three hours (measured), $\mathrm{Z2}=$ final cumulative infiltration rate after three hours (calculated graphically), $Z 3=$ final cumulative infiltration rate after three hours (predicted using C-Sharp application),

* Mean error $=\frac{\sum_{\mathrm{i}=1}^{\mathrm{i}=8}\left(\mathrm{Z1_{ \textrm {i } }}-\mathrm{Z} 3_{\mathrm{i}}\right)}{8}$ 
When the inputs variables of sand, silt, clay, water electric conductivity, water sodium adsorption ratio, soil electric conductivity, soil sodium adsorption ratio, organic matter in the soil, initial soil water content and soil bulk density, respectively were changed to be $80 \%, 13 \%, 7 \%, 3.25 \mathrm{dS} / \mathrm{m}, 7.6,10.86 \mathrm{dS} / \mathrm{m}, 8.2,1.34 \%, 10.32 \% \mathrm{db}$ and $1.49 \mathrm{~g} / \mathrm{cm}^{3}$ at changing time from 0 to 3 hours, the application was utilized to estimate cumulative infiltration rate at different times. However, Fig. (5) illustratescomparison between the measured and the estimated cumulative infiltration rate for such inputs. It is clear from Fig. (5)that the predicted constant $\kappa$ was $169.31 \mathrm{~mm} / \mathrm{hr} r^{\alpha}$ while the calculated one was $161.76 \mathrm{~mm} / \mathrm{hr} r^{\alpha}$ and the predicted constant $\alpha$ was 0.4788 while the calculated onewas 0.5399 as illustrated on Fig. (5).

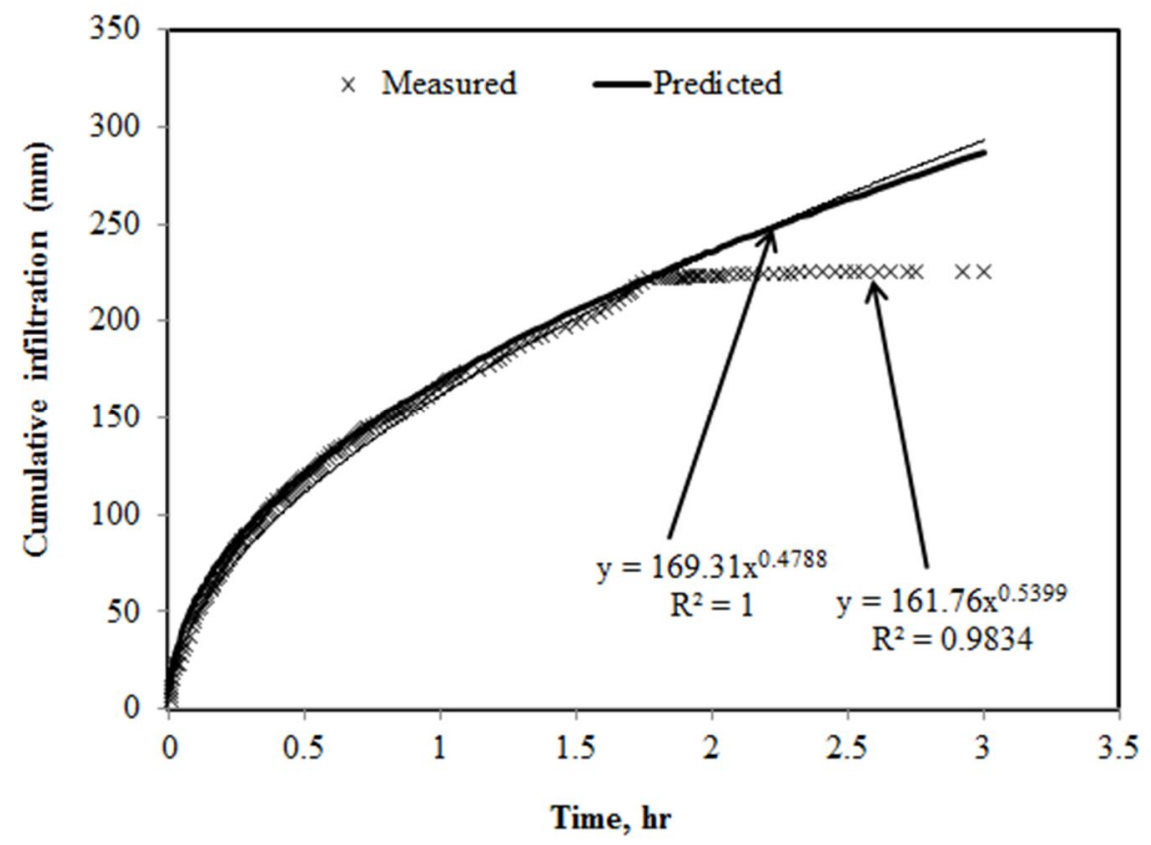

Fig. 5. Comparison between the measured and the predicted cumulative infiltration rate using the developed C-Sharp application (the inputs were $80 \%, 13 \%, 7 \%$, $3.25 \mathrm{dS} / \mathrm{m}, 7.6,10.86 \mathrm{dS} / \mathrm{m}, 8.2,1.34 \%, 10.32 \% \mathrm{db}$ and $1.49 \mathrm{~g} / \mathrm{cm}^{3}$ forsand, silt, clay, water electric conductivity, water sodium adsorption ratio, soil electric conductivity, soil sodium adsorption ratio, organic matter in the soil, initial soil water content and soil bulk density) at changing time from 0 to 3 hours.

\section{CONCLUSION}

In this work,the empirical constantsofcumulative infiltration rate equation ( $\alpha$ and $\kappa$ ) were predicted by developing two ANN models. Thefirst ANNmodel and the second ANN modelhad 20 and 25 neurons in the first hidden layer, respectively.However, the first and the second ANN models were used for prediction 
of the empirical constants $\kappa$ and $\alpha$, respectively. The inputsto ANN models wereelectric conductivity of soil, soil sodium adsorption ratio, initial soil water contents, soil texture index, soil bulk density, percentage of organic matter in the soil, electric conductivity of water and sodium adsorption ratio of water. For training of the ANNmodels, the graphically calculated data of the empirical constants ( $\alpha$ and $\kappa$ ) of cumulative infiltration rate equation corresponding to different soil and water characteristics were used. The comparison of calculated and predicted empirical constants ( $\alpha$ and $\kappa$ ) by ANN modelsshowed goodagreement in both training and testing stages. The weights of the trained ANN models were formulated and an interactiveC-Sharp application was built to predict the cumulative infiltration rate and it was tested displaying that it could be a useful tool in irrigation and soil studies.

\section{ACKNOWLEDGEMENTS}

The authors are grateful to King Abdulaziz City for Science and Technology (KACST) for funding of the research project (Grant No. ARP-33-51). Also, the authors are grateful to ElBahloul Abdussalem, Lecture of programing, Shaqra University, Community College, Huraimla, Saudi Arabia for his valuable work in building C-Sharp application.

\section{REFERENCES}

1. Al-Sulaiman, M. A. ; A. M. Aboukarima and M. F. Zayed. 2015.Prediction of Kostiakov parameters of cumulative infiltration based on soil and water characteristics. Egyptian J. Agric. Res., 93(5A): 273-291 (In Arabic).

2. Altendorf, C. T.; R. L. Elliott; E. W. Stevens and M.L. Stone. 1999. Development and validation of a neural network model for soil water content prediction with comparison to regression techniques. Trans. ASAE, 42(3):691-699.

3. Ayers, R. S. and D. W. Westcot. 1994. Water quality for agriculture. FAO IRRIGATION, Food and Agriculture Organization of the United Nations Rome.

4. Franzluebbers, A.J. 2002. Water infiltration and soil structure related to organic matter and its stratification with depth. Soil \& Tillage Research, 66:197-205.

5. Haghnazari, F.; H. Shahgholi and M. Feizi. 2015. Factors affecting the infiltration of agricultural soils: review. International Journal of Agronomy and Agricultural Research (IJAAR), 6(5):21-35.

6. Haykin, S. 1999. Neural Networks: a comprehensive foundation, Second Edition, Prentice Hall, 842pp. 
7. Jejurkar, C. L. and M. P. Rajurkar.2015. An investigational approach for the modeling of infiltration process in a clay soil. KSCE Journal of Civil Engineering,19(6):1916-1921.

8. Khaliq, A.; M.Iqbal andS.Anwar.1994.Evaluation of Kostiakov infiltration equation parameters from irrigation advance in level basins. Pak. J. Agri. Sci., 31(3):258-264.

9. Kostiakov, A. N. 1932. On the dynamics of the coefficient of water percolation in soils and on the necessity of studying it from a dynamic point of view for the purposes of amelioration. Trans. Com. Int. Soc. Soil Sci. 6th Moscow A: 17-21.

10. Lili, M.; V. F. Bralts; P. Yinghua; L. Han and L. Tingwu. 2008. Methods for measuring soil infiltration: State of the art. Int J Agric \& Biol Eng., 1 (1):22-30.

11. Mattar, M. A.; A. A. Alazba and T. K. Zin El-Abedin. 2015. Forecasting furrow irrigation infiltration using artificial neural networks. Agricultural Water Management, 148:63-71.

12. Mazloom, H. and $H$. Foladmand. 2013. Evaluation and determination of the coefficients of infiltration models in Marvdasht region, Fars province. International Journal of Advanced Biological and Biomedical Research,1(8):822829.

13. Moroke, T.; O. Dikinya and C. Patrick. 2009. Comparative assessment of water infiltration of soils under different tillage systems in eastern Botswana. Physics and Chemistry of the Earth, Parts A/B/C, 34(4):316-323.

14. Myburgh, P. and C. Howell. 2012. Possible causes of infiltration problems in drip irrigated vineyards in the Breede River valley. http://www.wineland.co.za/technical/possible-causes-of-infiltration-problems-indrip-irrigated-vineyards-in-the-breede-river-valley.

15. Oskoui, K. E. and S. J. Harvey. 1992. Predicting cone index from soil physical properties and organic matter content. ASAE Paper No. 92-1056, ASAE, St. Joseph, Michigan, USA:1-16.

16. Post, E. 2007. Designing and implementing a grid application for cumulative agrichemical residue tracking using third-party data sources and software components. Journal of Research and Practice in Information Technology,39(2):125-136.

17. Singh, S. K.; C. Lal; D. K. Sharma; S. Mathur; N. C. Shahi and K. Chand. 2013. Comparison of measured and predicted evapotranspiration using artificial neural network model. J. Acad. Indus. Res., 1(12):816-819. 
18. Skandarinia, A.; M.Z. Ahmadi; H. Nazarpour; M. Teimori and M. Z. Moshfegh. 2005. Investigation of the effects of previous rainfall factor in estimating of stream flow using the modeling of rainfall-runoff. Eight International Congress of Civil Engineering, Shiraz University, 12 May 2005.

19. Suarez, D. L. ; J. D. Wood and S. M. Lesch. 2008. Infiltration into cropped soils: effect of rain and sodium adsorption ratio-impacted irrigation water. Journal of Environmental Quality,Supplement, 37(5):169-179.

20. Uloma, A. R.; A. C. Samueland I. K. Kingsley. 2014. Estimation of Kostiakov's infiltration model parameters of some sandy loam soils of Ikwuano - Umuahia, Nigeria. Open Transactions On Geosciences, 1(1):34-38.

21. Vesta Services, Inc. 2000. Qnet2000 Shareware, Vesta Services, Inc., 1001 Green Bay Rd, STE 196, Winnetka, IL 60093. 


\title{
تطبيق حاسوبي تفاعلي باستخدام لغة السي شارب للتنبؤ بتسرب

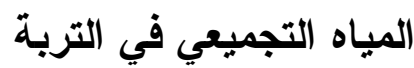

\author{
محمد عبد العزيز السليمان' عبد الواحد محمد أبوكريمة' \\ ا ـ كلية المجتمع بحريملاء، جامعة شقراء، المملكة العربية السعودية

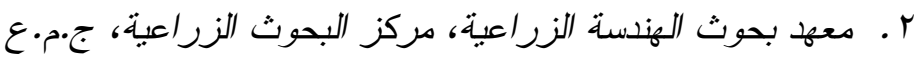

هدفت الدر اسة إلى تطوير تطبيق حاسوبي تفاعلي باستخدام لغة الحاسوب التفاعلية المسماة

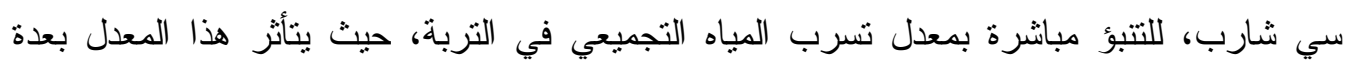

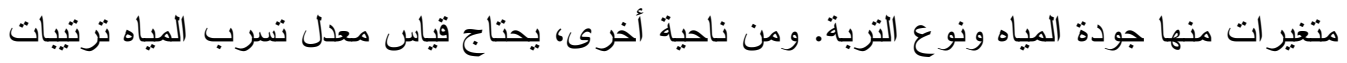

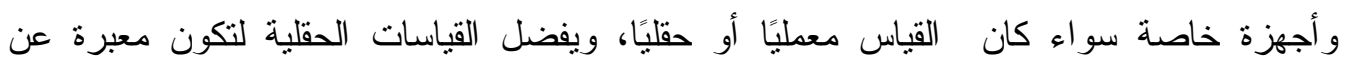
القياسات الفعلية، ولكن إجر ائها في الحقل ينطلب أجززة وتكاليف مادية، لذا من الأفضل تطوير وسيلة للتتبؤ بتسرب المياه التجميعي في التربة بطريقة فعالة ودقيقة. وفي هذه الدراسة استخدمت الحلقة المزدوجة في قياس تسرب المياه في الحقل حتى ثلاث ساعات في ترب مختلفة مابين رملية ورملية

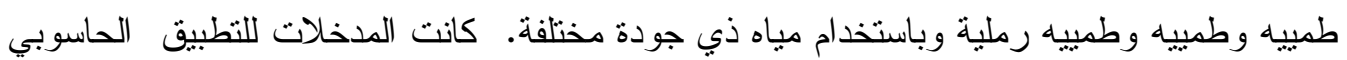

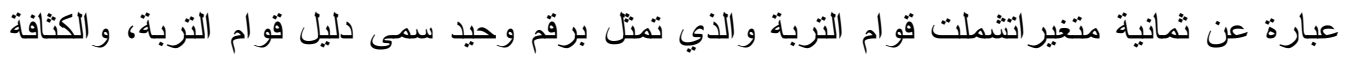
الظاهرية للتربة و المحتوى الرطوبي الابتدائي للتربة ونسبة المادة العضوية بالتزبة و الموصلية

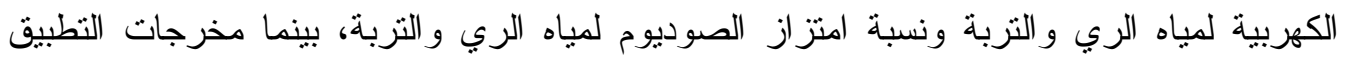
عبارة عن معدل التسرب التجميعي للمياه في التربة عند الزمن المحدد وحتى ثلاث ساعات. ومن لناه

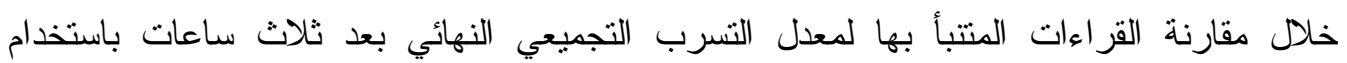
النطبيق الحاسوبي بالقر اءات الفعلية، وجد أن متوسط الخطأ يساوي 39.25- مم، لذا يوصى باستخدام التطبيق الحاسوبي المطور في إدارة المياه من خلال التنبؤ بمعدل تسرب المياه التجميعي في التربة. 